\title{
Influence of Free Fatty Acids as Additives on the Crystallization Kinetics of Cocoa Butter
}

\author{
Miriam Müller ${ }^{1} \&$ Enrico Careglio ${ }^{1}$ \\ ${ }^{1}$ Trier University of Applied Sciences, Department of Food Technology, Schneidershof, D-54295 Trier, Germany \\ Correspondence: Miriam Müller, Trier University of Applied Sciences, Department of Food Technology, \\ Schneidershof, D-54295 Trier, Germany, Tel: 490-651 / 8103-286. E-mail: M.Mueller@blv.hochschule-trier.de
}

Received: June 21, 2018

doi:10.5539/jfr.v7n5p86

\author{
Accepted: July 6, 2018 Online Published: August 9, 2018 \\ URL: https://doi.org/10.5539/jfr.v7n5p86
}

\begin{abstract}
In this study, the influence of free fatty acids as additives on the crystallization kinetics of cocoa butter (CB) and the industrial tempering was considered for the first time. Different concentrations $(0.5 \%-5.0 \%)$ of stearic, palmitic and oleic acid were added to $\mathrm{CB}$ and crystallized at isothermal temperatures between $18-28{ }^{\circ} \mathrm{C}$. To imitate the industrial tempering, $\beta$-crystals were actively formed using a temper. The solid fat content (SFC) was determined by pulsed NMR with data fitted to the Gompertz equation and melting temperature and polymorphic behaviour were analysed by DSC. With an increase in temperature of $2-5^{\circ} \mathrm{C}$ a reduction in crystallization rate of 40-80 \%, lower solid fat contents and 1,5-6 times longer induction times occur. The SFC of tempered blends are significantly lower $(\mathrm{P}<0.05 \%)$ than their non-tempered counterparts independent of the crystallization temperature. At higher temperatures, palmitic acid and especially stearic acid act as a crystallization initiator due to their higher melting point of 63 and $69{ }^{\circ} \mathrm{C}$, indicating shorter induction times with increasing free fatty acid content. Although pure CB crystallizes fastest, an increasing stearic acid content leads to higher crystallization rates. In contrast, palmitic and oleic acid have retarding effects. Thus, while under spontaneous conditions a temperature dependence was ascertained, after pre-crystallization the free fatty acid concentration could be identified as the driving force in terms of crystallization rate.
\end{abstract}

Keywords: cocoa butter, crystallization kinetics, free fatty acids, polymorphism, tempering

\section{Introduction}

The optical quality of a product is one of the most important criteria in the consumer's purchasing decision. The desired luster and the consumers' appreciation of the "crack" of chocolate requires perfect crystallization and high quality cocoa butter (CB). However, CB can differ in triacylglyceride (TAG) composition and content of minor components due to different factors like environmental conditions (eg. Geographical region), ripeness of cocoa beans, fermentation conditions and microbiological nature (Chaiseri \& Dimick, 1989; Ziegleder, 1995). In addition, further processing such as refining or deodorization can decisively influence the minor component spectrum (Lechter, 2012).

Crystallization can be affected by the minor components of $\mathrm{CB}$, including monoglycerides- (MOG), diglycerides (DAG), free fatty acids (FFA), phospholipids, hydrocarbons, sterols and sterol esters, tocopherols and many others (Lipp \& Anklam, 1998; Foubert, Vanrolleghem, Thas, \& Dewettinck, 2004; Chaiseri \& Dimick, 1989; Ziegleder, 1995). According to Smith, Bhaggan, Talbot and van Malssen (2011) there is no accepted concentration of components that influence crystallization. It depends on their structure, whether and to what extent the crystallization is influenced by the minor component. For example, Herrera and Rocha (1996) showed that incorporation into the crystal requires a concentration of 0.5-5.0\% to affect crystallization; if the minor component is involved in nucleation, $0.1 \%$ is sufficient to obtain significance. Not only nucleation, but also crystal growth can be hindered by minor components blocking the growth sites on the crystal surface.

TAGs as one of the main components in CB, determine the crystallization behavior of CB. Nevertheless, fats with an identical TAG profile show differences in their crystallization kinetics, in the equilibrium solid fat content (SFC) and in the microstructure. These differences can be attributed to the minor component profiles of CB (Lechter, 2012). In order to explain these alterations, the spectrum of minor components and their mode of action has to be investigated more precisely, which will be discussed later in more detail focussing on the influence of FFA. 
Recently, the impacts of FFA content on fat systems has been reviewed, however the focus was exclusively on either FFA content reduction or their effects on the crystallization kinetics and the SFC of CB. For instance, Ayala et al. (2007) showed a linear increase in SFC with a decrease in the FFA content at a temperature range of $20{ }^{\circ} \mathrm{C}, 25^{\circ} \mathrm{C}$ and $30^{\circ} \mathrm{C}$. The difference in the SFC does not correspond to the amount of uncrystallised FFA. Besides the FFAs, there are additional uncrystallised TAGs that explain the lower SFC value. Jacobsberg and Ho (1976) noted that an increase in FFA content in palm oil leads to lower SFC values and lower melting points caused by eutectic formation. This is in agreement with newer findings by Calliauw et al. (2008), who explained the formation of higher amounts of $\alpha$-crystals at $20^{\circ} \mathrm{C}$ in strongly refined $\mathrm{CB}$ compared to 'pure' $\mathrm{CB}$ with the formation of an eutectic mixture.

In addition to the clear correlation of the SFC, a linear dependence of the induction time on the FFA concentration could be observed (Calliauw et al., 2008; Lechter, Widlak, Sikorski, \& Karcher, 2011). A transformation from $\alpha$ - to $\beta^{\prime}$-crystals also occurred earlier at lower FFA concentration. Pontillon (1998) found that FFAs at a concentration above $2 \%$ prolonged the crystallization time of CB.

Most studies have only investigated FFA contents as a mixture of different unnamed fatty acids; however, information about their exact composition is still missing. Only a few studies had pointed out the importance of the mode of action of FFA as additives:

Loisel, Lecq, Keller, Bourgaux and Ollivon (1998), for example, showed that higher levels of free stearic acid (S) decelerate the crystallization of monounsaturated triglycerides in chocolate. Smith, Cebula and Povey (1994) concluded from their study on the influence of lauric acid-based molecules on the crystallization of trilaurin (LLL) that free lauric acid (L) increases the growth rate of LLL, but reduces the size and variety of crystals formed. The influence of minor components on the crystallization of coconut oil was part of a study by Gordon and Rahman (1991). They found that the crystallization rate was reduced with increasing FFA content at $15^{\circ} \mathrm{C}$. Both lauric and oleic acids $(\mathrm{O})$ showed a marked delay in the onset of crystallization, while palmitic acid (P) caused only a small effect. Tietz and Hartel (2000) claimed that an optimum concentration of minor components exists with regard to desired or observed effects during the crystallization of fats. However, it is not sufficiently studied yet, if this thesis would also apply to actively added FFAs.

In this study, it is aimed to investigate the effects of free fatty acids as additives on the crystallization kinetics of CB. Also, tempering as a processing step was studied to better understand the effects on the crystallization, yet no study has confirmed this to our knowledge.

\section{Material and Method}

\subsection{Material}

The used cocoa butter has a FFA content of $<0.05 \%$ and was purchased from Cargill, Netherlands. The used fatty acids are stearic acid (S) and palmitic acid (P) with a purity of $>95 \%$ from Sigma Aldrich ${ }^{\circledR}$ and oleic acid (O) with a purity of $>90 \%$ from Alfa Aesar®.

To examine the influence of the different FFAs on the crystallization kinetics of cocoa butter, free fatty acid cocoa butter blends (FFA CB blends) of different concentrations $(0 \%, 1.5 \%, 3.0 \%, 5.0 \%)$ were prepared.

\subsection{Sample Preparation}

\subsubsection{Crystallization at Spontaneous Conditions}

To explore the natural affinity of the FFA CB blends for crystal formation the samples were melted at $80{ }^{\circ} \mathrm{C}$ for $15 \mathrm{~min}$. in order to eliminate all the crystals and counteract the memory effect (Foubert, Vanrolleghem, \& Dewettinck, 2003a). Subsequently, samples were cooled to crystallization temperature $\left(18{ }^{\circ} \mathrm{C}, 20{ }^{\circ} \mathrm{C}, 23{ }^{\circ} \mathrm{C}\right.$ and $28{ }^{\circ} \mathrm{C}$ ) by applying appropriate temperature control.

\subsubsection{Crystallization at Pre-crystallized \& Spontaneous Condition}

In order to explore the influence of industrial pre-crystallization on the FFA CB blends and their crystallization kinetics, the samples were pre-crystallized in a tempering machine to form the more stable $\beta$-crystals. The previously melted FFA CB blends $\left(80^{\circ} \mathrm{C}, 15 \mathrm{~min}\right.$.) were transferred at $80^{\circ} \mathrm{C}$ to the temper and cooled under shear (shear rate $\dot{\gamma}=9 \mathrm{~s}-1$ ) to $27-28{ }^{\circ} \mathrm{C}$. When reached to the desired crystal nuclei content of $0.2 \%$ to $0.7 \%$, the samples were stored at the crystallization temperatures $\left(18^{\circ} \mathrm{C}, 20^{\circ} \mathrm{C}, 23^{\circ} \mathrm{C}\right.$ and $\left.28^{\circ} \mathrm{C}\right)$ for further analysis.

\subsection{Pulsed NMR}

The minispec mq 20 from Bruker, Germany was used to detect the SFC per time. Calibration was performed using three Bruker SFC calibration standards $(0 \%, 30.2 \%, 74.3 \%)$. For the preparation of the crystallization 
curves, the SFC was detected as a function of time using the direct method according to DIN EN ISO 8292-1. Two approaches were measured in triplicates as shown in Table 1.

Table 1. Measuring times for the preparation of the crystallization curves by means of pulsed NMR

\begin{tabular}{lll}
\hline Interval & Duration & Pulsing \\
\hline I & $0-50 \mathrm{~min}$ & every $5 \mathrm{~min}$ \\
II & $50-120 \mathrm{~min}$ & every $10 \mathrm{~min}$ \\
III & $120-420 \mathrm{~min}$ & every $30 \mathrm{~min}$ \\
IV & $24 \mathrm{~h}-120 \mathrm{~h}$ & every $24 \mathrm{~h}$ \\
V & $1 \mathrm{~W}-4 \mathrm{~W}$ & every week \\
\hline
\end{tabular}

\subsection{DSC}

DSC (Mettler Toledo, Germany and the STARe Basis Software V. 11) was used to analyze the melting and crystallization properties of the blends. $10 \pm 2 \mathrm{mg}$ of fat were transferred to $40 \mu \mathrm{l}$ aluminium pan, sealed hermetically and heated to $80^{\circ} \mathrm{C}$ for $15 \mathrm{~min}$. After immediate cooling to the required examination temperature of $18{ }^{\circ} \mathrm{C}, 20^{\circ} \mathrm{C}, 23{ }^{\circ} \mathrm{C}$ and $28^{\circ} \mathrm{C}$ followed by defined times of isothermal crystallization, subsequent melting at $3{ }^{\circ} \mathrm{C} / \mathrm{min}$ to $70^{\circ} \mathrm{C}$ was applied (Foubert, Fredrick, Vereecken, Sichien, \& Dewettinck, 2008). An empty pan was used as a reference and a two-point temperature calibration was performed using indium and cyclohexane. The DSC analysis was performed in triplicates.

\subsection{Conditions of Pre-crystallization}

The degree of tempering is determined by the method of Schuster-Salas and Ziegleder (1992). A pre-crystallized sample was melted from $26{ }^{\circ} \mathrm{C}$ to $45^{\circ} \mathrm{C}$ with $10{ }^{\circ} \mathrm{C} / \mathrm{min}$. The amount of $\beta_{\mathrm{V}}$-crystals was calculated by using the following formula:

$$
f=\frac{P \cdot 100 \cdot 100}{H \cdot F}
$$

where $f$ stands for crystallized fat in $\%, P$ for enthalpy of the melting peak in $\mathrm{J} / \mathrm{g}, F$ for fat content in $\%$ and $H$ for enthalpy of fusion in $\mathrm{J} / \mathrm{g}$ (Crystal " $\left.\beta_{\mathrm{v}} "=137 \mathrm{~J} / \mathrm{g}\right)$. In order to avoid thermal influence, all utensils used are tempered to $26^{\circ} \mathrm{C}$.

\subsection{Crystallization Kinetics}

Various models can be applied to describe the crystallization kinetics of fats, such as the Gompertz (Kloek, Walstra, \& Vliet, 2000; Vanhoutte, Dewettinck, Foubert, Vanlerberghe, \& Huyghebaert, 2002) (Figure 1) and the Foubert model (Foubert, Vanrolleghem, Vanhoutte, \& Dewettinck, 2002; Foubert, Dewettinck, \& Vanrolleghem, 2003b) or the most commonly used Avrami model (Herrera, de Leon Gatti, \& Hartel, 1999; Foubert et al., 2002; Foubert et al., 2003b).

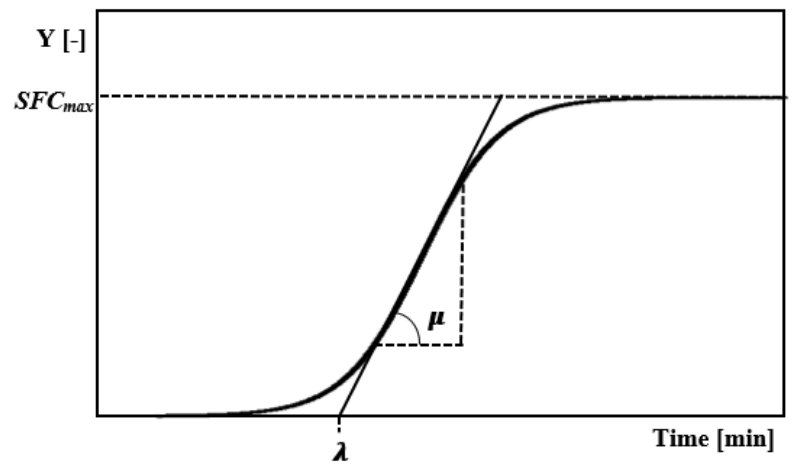

Figure 1. Visual presentation of the Gompertz parameters (modified according to Zwietering, Jongenburger, Rombouts, \& Van't Riet, 1990), Y=solid fat content, $\mathrm{SFC}_{\max }=$ maximum solid fat content, $\boldsymbol{\mu}=$ crystallization rate and $\lambda$ =induction time

The latter is more suitable for the fit of one-step crystallization processes (MacNaughtan, Farhat, Himawan, Starov, \& Stapley, 2006), while the Gompertz model can also be used to describe multi-step crystallization processes and provides a better fit compared to Avrami (Kloek et al., 2000; Vanhoutte et al., 2002; Foubert et al., 
2002; Foubert et al., 2003b). Moreover, in the case of Avrami, $\mathrm{k}$ has the unit $\min ^{-\mathrm{n}}$. Thus different k-values are difficult to compare because their units can have different dimensions (Campos \& Marangoni, 2012). For this reason the Gompertz model has been utilized to describe the crystallization curves:

$$
Y=S F C_{\max } \cdot \exp \left\{-\exp \left[\frac{\mu \cdot e}{S F C_{\max }}(\lambda-t)+1\right]\right\}
$$

where $\mathrm{SFC}_{\max }$ represents the maximum achievable $\mathrm{SFC}$ in $\%, \boldsymbol{\mu}$ the crystallization rate in $\% / \mathrm{min}$ (defined as the slope of the tangent at the inflection point), $\lambda$ the induction time in min. (defined as the intersection of the tangent with the $\mathrm{x}$-axis) and $\mathrm{t}$ the time in min.

\section{Results and Discussion}

\subsection{Crystallization Kinetics of Pure Cocoa Butter}

The crystallization of pure CB was determined by pulsed NMR, whereby the increase in SFC has been measured as a function of time. The crystallization of pure $\mathrm{CB}$ under spontaneous conditions only at $18{ }^{\circ} \mathrm{C}$ and $20{ }^{\circ} \mathrm{C}$ shows a two-step crystallization. After a short lag period, a first plateau was detected followed by a sharp increase in SFC and a second plateau, which represents the $\mathrm{SFC}_{\max }$ (Figure 2). The Gompertz model was applied for both plateaus.
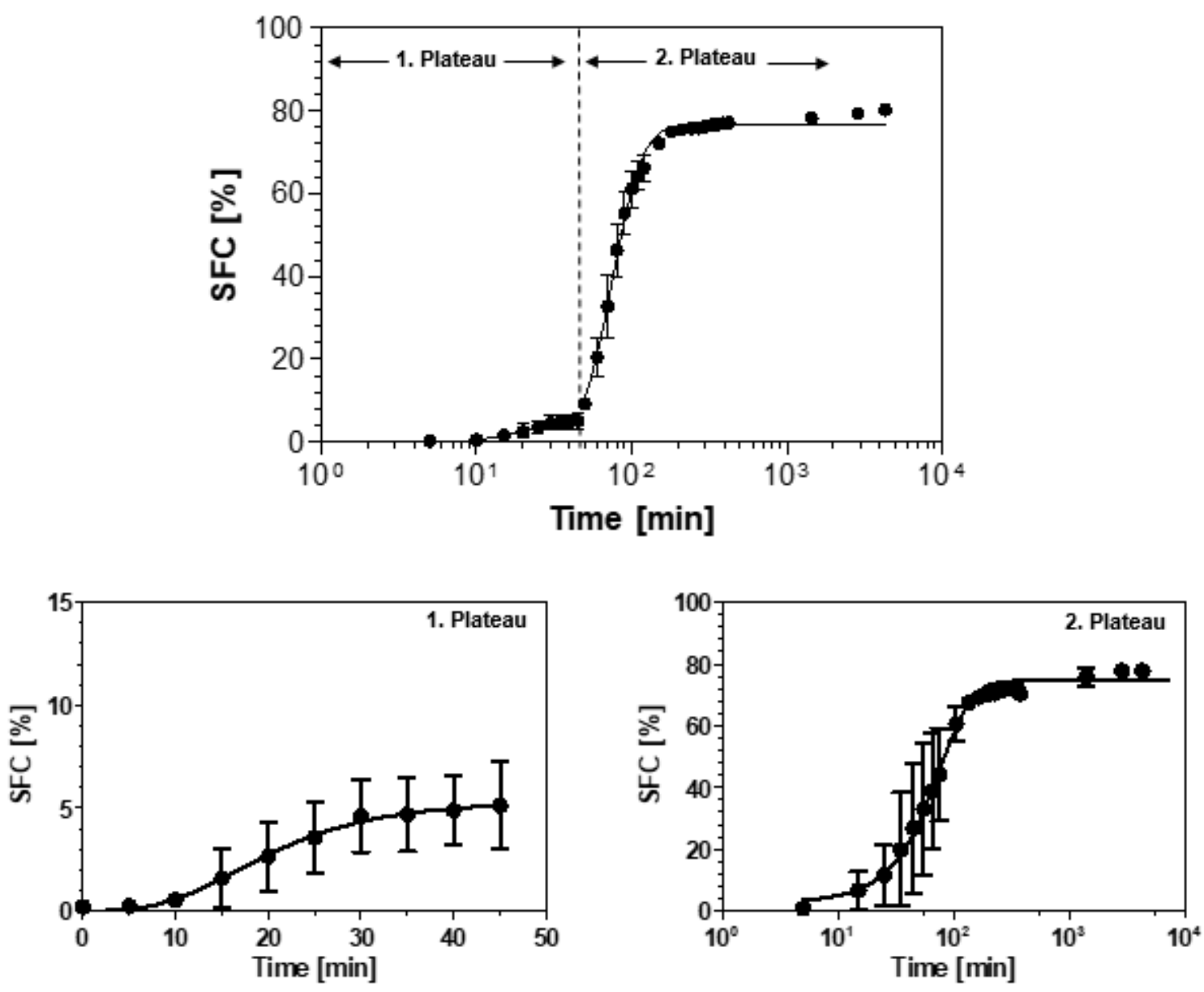

Figure 2. Application of the Gompertz model to a two-step crystallization at isothermal conditions

Due to the complexity of the composition of fats, such two-step crystallization curves may arise in consequence of the formation of different polymorphic forms or the crystallization of different fractions (Dewettinck, Foubert, Basiura, \& Goderis, 2004). At higher temperatures, this phenomenon does not occur. The threshold between one-step and two-step crystallization depends on the composition of the CB (Marangoni \& McGauly, 2003; Dewettinck et al., 2004; Padar, Jeelani, \& Windhab, 2008). The studies point to a limit of about $23{ }^{\circ} \mathrm{C}$, which 
confirms the results of Foubert et al. (2004). The low activation energy of the $\alpha$-polymorph plays a decisive role in the formation of a two-step crystallization. In the first step, parts from the melt crystallize in the $\alpha$-modification, while in a second step a solid-solid transformation of the formed $\alpha$-crystals into the more stable $\beta^{\prime}$-forms was achieved (Marangoni \& McGauly, 2003; Foubert et al., 2004).

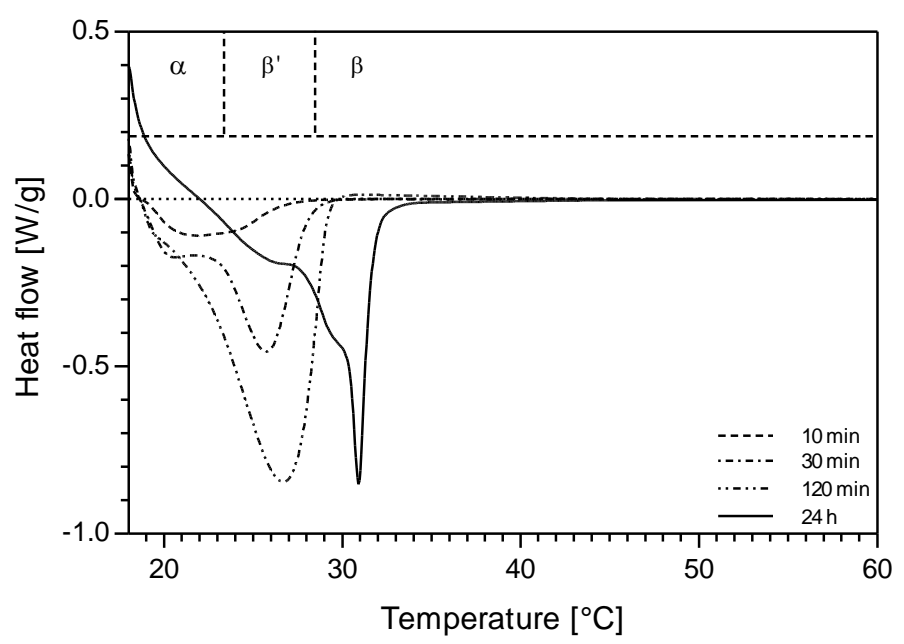

Figure 3. DSC melting curves of pure cocoa butter after isothermal crystallization at $18{ }^{\circ} \mathrm{C}$

The maximum peak temperatures measured with DSC confirmed the results of the change in polymorph from $\alpha$ to $\beta^{\prime}$ and $\beta$ with the shift of the melting temperature to higher temperatures. (Figure $3 \& 4 \mathrm{C}$ ). In addition, a dependency of the crystallization rate on the cooling temperature was recorded. As the crystallization temperature increases, the crystallization rate decreases (Figure 8). Furthermore, it can be seen that the $\mathrm{SFC}_{\max }$ of the different samples is also strongly influenced: the higher the temperature the lower the $\mathrm{SFC}_{\max }($ Figure 5). The duration until reaching the $\mathrm{SFC}_{\max }$ also increases with increasing temperature. 

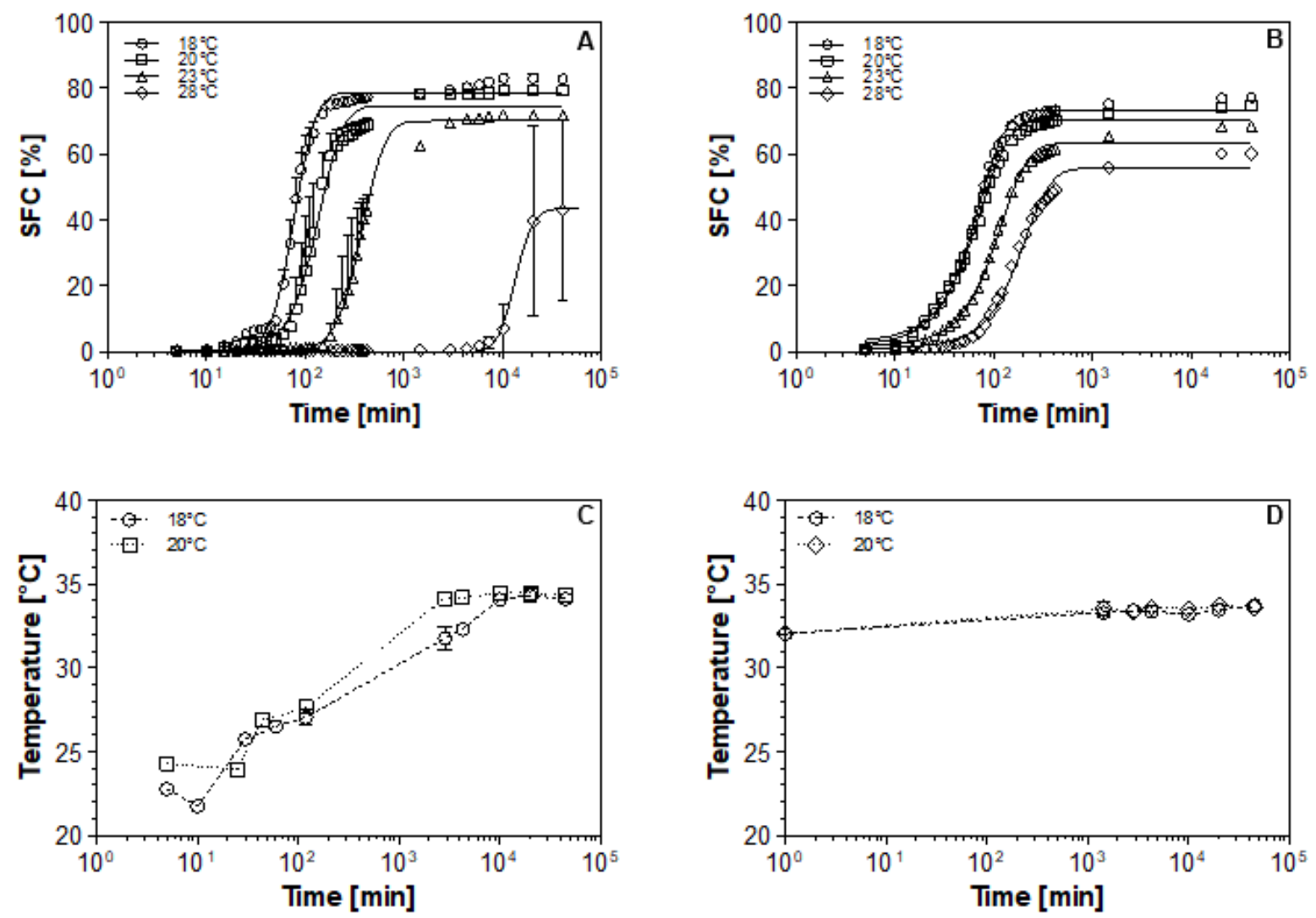

Figure 4. Crystallization curves (A-B) and peak temperatures (C-D) of pure cocoa butter at spontaneous and tempered conditions

Pre-crystallization of the samples and subsequent isothermal storage leads to one-step crystallization without first plateau (Figure 4B). The formation of native $\beta$-crystals shows accelerated crystallization rates and shorter times to reach $\mathrm{SFC}_{\max }$. Crystallization begins immediately, as the higher-melting crystals formed during the tempering process now proceed as seed and initiate crystallization. The peak temperature of about $33{ }^{\circ} \mathrm{C}$ indicates polymorphic forms in the $\beta$-configuration (Figure 4D). However, it is noticeable that the tempered samples have a lower $\mathrm{SFC}_{\max }$ value than the non-tempered ones, regardless of the crystallization temperature (Figure 5). Maybe the rearrangement into next higher polymorphic forms leads to the incorporation of additional fat molecules rather than a direct arrangement in $\beta$-modification.

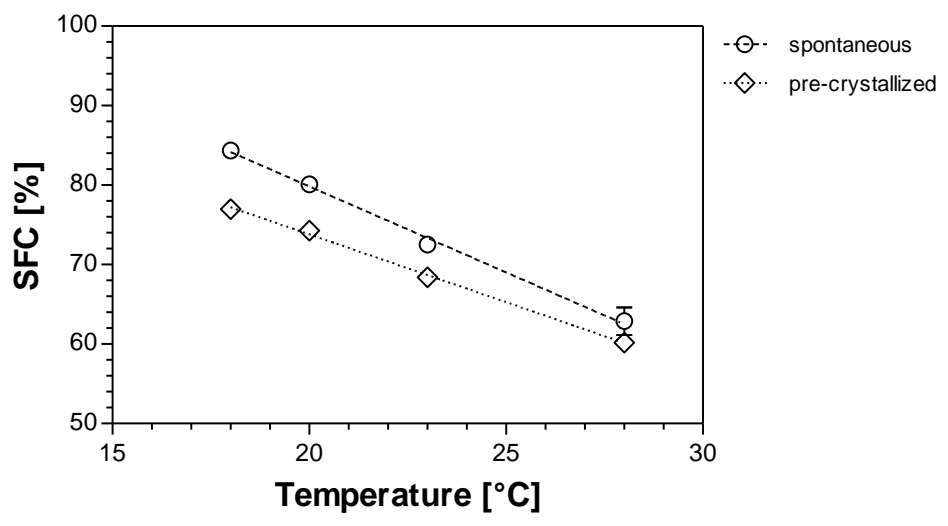

Figure 5. SFC as a function of the temperature at spontaneous and pre-crystallized conditions 


\subsection{Crystallization Behaviour of Free Fatty Acid Cocoa Butter Blends}

\subsubsection{Influence on Temperature}

The crystallization behavior of FFA CB blends also shows a dependence on the crystallization temperature, similar to pure CB. Both at spontaneous conditions and after pre-crystallization, lower SFCs emerge with increasing temperature. In this case, a significant difference in the SFC between the spontaneously crystallized blends and its pre-crystallized counterparts can also be determined. However, addition of FFA leads to a reduction of the $\Delta$-SFCs up to $23{ }^{\circ} \mathrm{C}$, i.e. the higher the FFA content, the lower the difference between spontaneous and pre-crystallized samples in terms of their maximum SFC (Figure 6). The added fatty acids affect the pre-crystallized samples, while the $\mathrm{SFC}_{\max }$ remains largely unaffected under spontaneous conditions. The change of the $\mathrm{SFC}_{\max }$ under pre-crystallized conditions does not correspond to the added amount of FFA, similar to the results of Ayala et al. (2007).

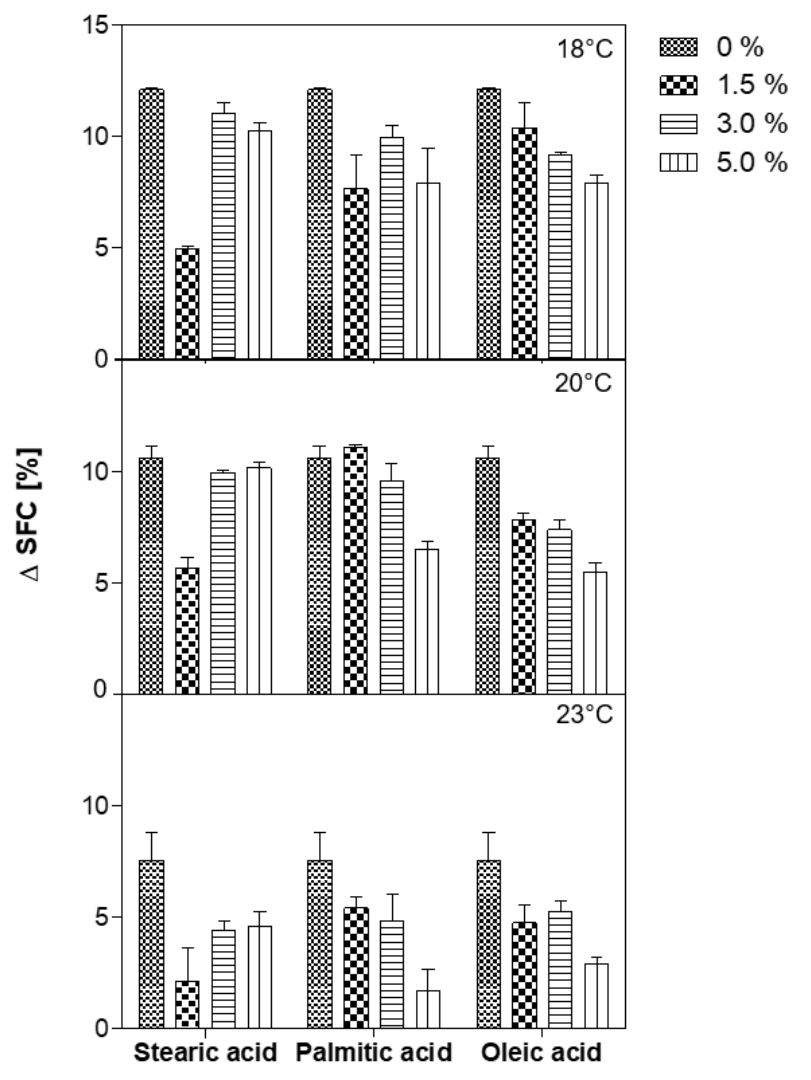

Figure 6. $\Delta$-SFC between spontaneously crystallized and pre-crystallized FFA CB blends at 18,20 and $23{ }^{\circ} \mathrm{C}$

An increase in the crystallization temperature leads to longer induction times (Figure 7) and lower crystallization rates. After semi logarithmic plotting of induction time versus temperature, an exponential correlation in the range of $18-28{ }^{\circ} \mathrm{C}$ can be observed $\left(\mathrm{R}^{2}>0.9874\right)$. However, the study by Ziegleder (1990) on isothermal crystallization of $\mathrm{CB}$ showed a linear dependence of the onset time (intersection of the tangent at the inflection point of the DSC curve with the baseline) with increasing temperature $\left(20-23{ }^{\circ} \mathrm{C}\right)$. Certainly, the curve at lower temperatures also exhibits exponential tendency. 


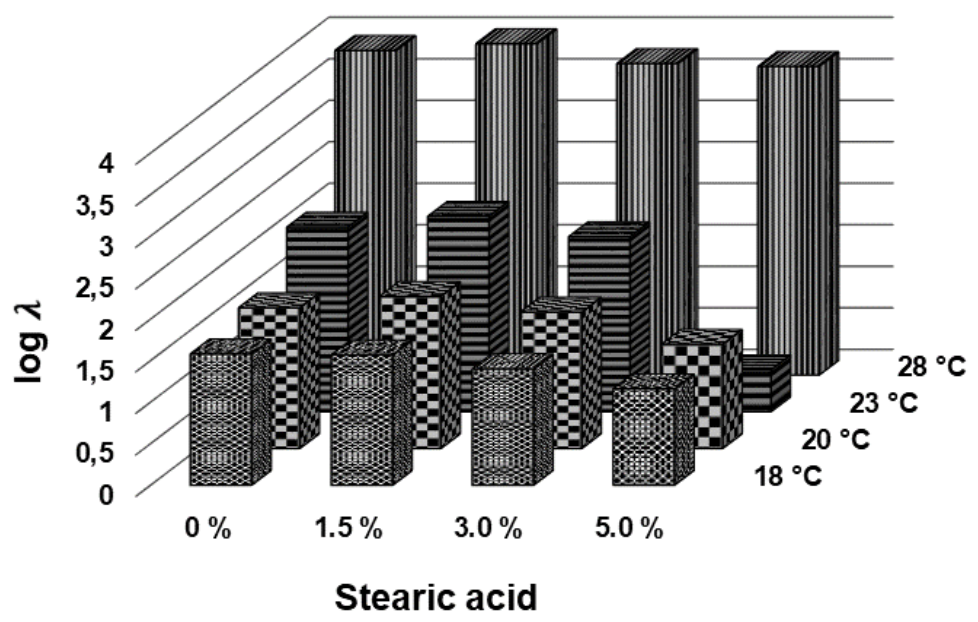

Figure 7. Induction time of the stearic acid blends and their dependence on temperature and concentration

The crystallization rate also correlates with temperature under both spontaneous and pre-crystallized conditions. An exponential decrease has been observed (Figure 8).

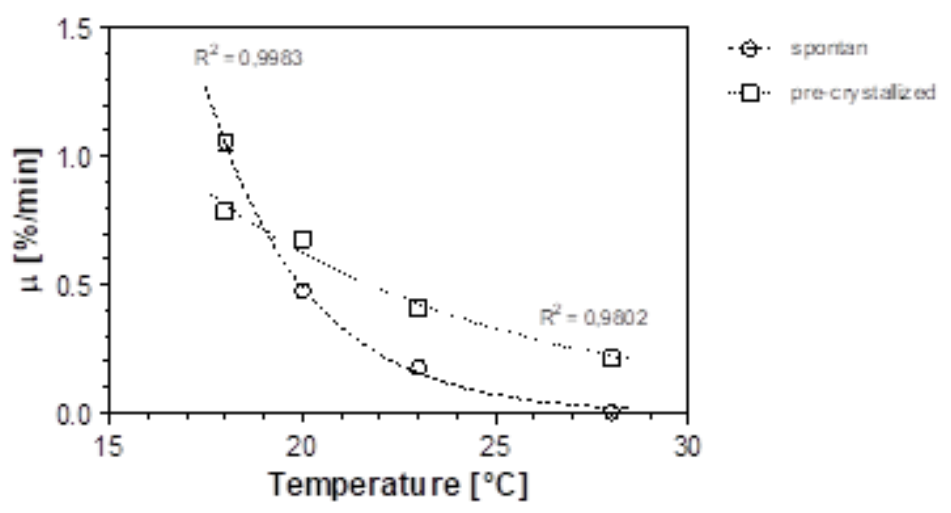

Figure 8. Crystallization rates of pure cocoa butter as a function of temperature at spontaneous and pre-crystallized conditions

Additionally, longer induction times of the $\alpha$ - to $\beta$ '-transformation can be detected under spontaneous conditions. The height of the first plateau also decreases with increasing temperature (Figure 3A).

Comparable results of the SFC after the first-plateau were reported by Herrera et al. (1999) and Vanhoutte et al. (2002) for milk fat. Marangoni and McGauley (2003) found lower equilibrium SFCs for pure CB at higher temperatures.

\subsubsection{Influence of the Fatty Acid}

Depending on the FFA used, different effects regarding the crystallization kinetics can be found:

A significant change of the SFCs with the addition of FA under spontaneous conditions could be determined only at a crystallization temperature of $28{ }^{\circ} \mathrm{C}$, thus the effect of FFA does not influence the maximum SFC under spontaneous conditions. Furthermore, only a significant difference in the SFC could be detected with an addition of $5 \%$ FFA. The oleic acid blends show lower values $(p<0.05)$ than the equivalent stearic acid and palmitic acid blends. Under pre-crystallized conditions, oleic acid has the strongest effects on the SFC. There is a significant decrease with increasing concentration $(\mathrm{p}<0.05)$. While palmitic acid does not affect SFC, stearic acid has significantly higher SFCs the higher the concentration $(\mathrm{p}<0.05)$. A comparison of the fatty acids of the same concentration shows only a significance for the oleic acid blends $(\mathrm{p}<0.05)$.

According to Smith et al. (2011) there are two ways in which additives can manipulate the final SFC. On the one 
hand, there may be a change in the equilibrium conditions by incorporation of the additive into the crystal or stabilization of the liquid phase by the added component. On the other hand, a kinetically stable state can be formed instead of a thermodynamic equilibrium. A kinetic factor is usually present when there is a temperature dependence (heating or subcooling) (Schlichter, Sarig, \& Garti, 1988).

With regard to the influence of the FFA addition on the formation of the first plateau, different effects can be seen for each FA used. While stearic acid and palmitic acid affect the height of the plateau with increasing concentration, an addition of oleic acid leads to a delayed crystallization start. An extension of the induction time can also be attributed to palmitic acid. Although palmitic and stearic acid blends have similar crystallization rates in the first plateau, extended periods of $\alpha$-polymorph formation occur compared to stearic acid blends due to the delayed crystallization start after the addition of palmitic acid. Not only does stearic acid initiate crystallization 60 to $90 \%$ earlier (depending on added stearic acid), but it also shortens the phase of $\alpha$-modification so that an earlier transformation to the next higher polymorphic forms can be achieved.

A comparison of the crystallization rate of pure CB with the FFA blends shows that the pure fat crystallizes fastest. An addition of FFA thus causes a reduction in speed. However, a difference in the used fatty acid can be detected. While stearic acid with increasing concentration leads to an acceleration of crystallization, palmitic and oleic acid ( $\mathrm{P}$ stronger than $\mathrm{O}$ ) show slowing effects. Under pre-crystallized conditions, an addition of free fatty acids causes similar behavior. Though, the crystallization is faster, because the already formed crystal nuclei act as seed and start the crystallization. Not only is this dependent on the concentration, but also on the crystallization temperature (Figure 9). Like pure CB, the FFA-CB blends show an exponential decrease in crystallization rate with increasing temperature under both spontaneous and pre-crystallized conditions. Depending on the blend, the slope of the curve and thus the effect of the temperature changes. The more free fatty acid is added, the lower its effect. However, under pre-crystallized conditions, a distinction must be made in terms of fatty acid: while the concentration of free stearic and palmitic acids superpose the effects of temperature, oleic acid leads to a greater influence of temperature. Under spontaneous conditions, the temperature is the driving force, whereas after a pre-crystallization a dependence on the FA-concentration can be observed.
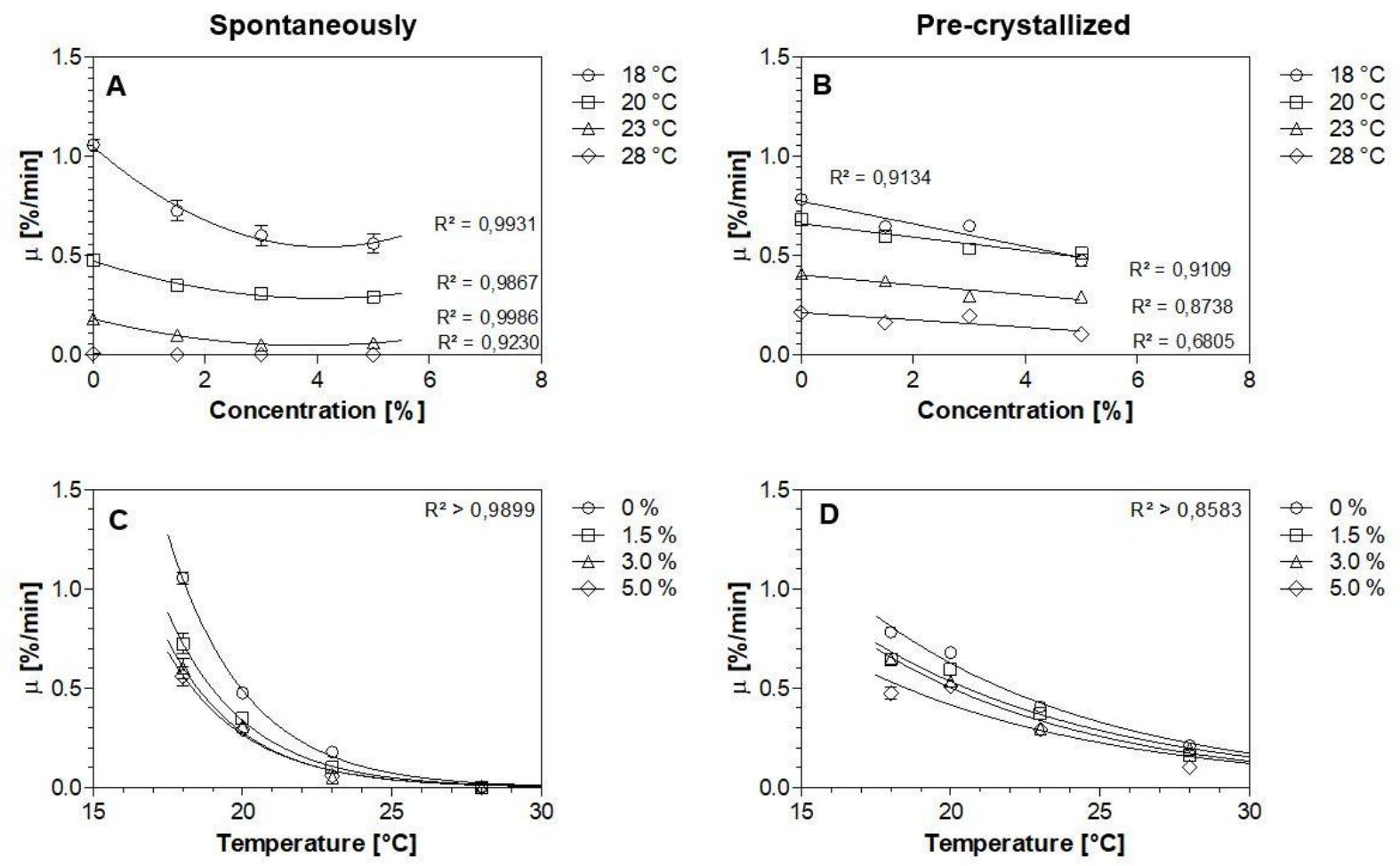

Figure 9. Dependence of the crystallization rate on the concentration (A-B) and the temperature (C-D) under spontaneous and pre-crystallized conditions of the palmitic acid cocoa butter blends

The lower the subcooling of the melt, the clearer the effect of the added fatty acid. In the range of $18{ }^{\circ} \mathrm{C}-23^{\circ} \mathrm{C}$, free palmitic acid leads to lower crystallization rates. At $28^{\circ} \mathrm{C}$, however, a slight acceleration is measurable. Due 
to the high melting point, palmitic acid acts as a crystallization nucleus and presumably forms additional growth sites, which accelerates crystallization. When considering the different concentrations, a minimal crystallization rate can be found in the range between 3.0\%-5.0\% palmitic acid addition (Figure 9A). Not only from a certain temperature, but also from a certain concentration of free fatty acids there is an acceleration of crystallization. Similar effects can also be attributed to stearic acid (not illustrated). Under pre-crystallized conditions, such a minimum crystallization rate is not apparent. In this case, there is a more or less linear dependence instead (Figure 9B).

Among higher crystallization rates, the addition of free stearic acid leads to lower induction times under spontaneous and pre-crystallized conditions. On the other hand, oleic acid has significant retarding effects (not illustrated). With a melting point of about $16{ }^{\circ} \mathrm{C}$, it is liquid at all investigated crystallization temperatures. Consequently, less crystallisable fat is available, which would explain the longer induction times. Palmitic acid shows different influences depending on the crystallization temperature. At temperatures up to $23{ }^{\circ} \mathrm{C}$, retarding effects can be observed, whereas crystallization at $28{ }^{\circ} \mathrm{C}$ starts earlier after the addition of palmitic acid. Acting as crystal seeds due to the higher melting point of palmitic acid could be the explanation again (Figure 10).
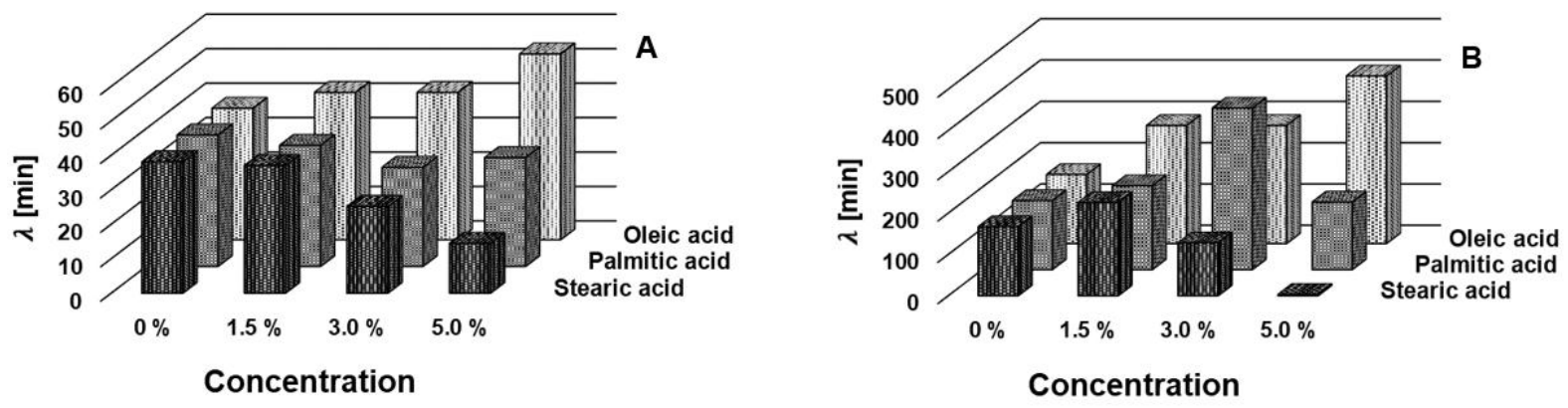

Figure 10. Induction time of FFA CB blends with different concentrations at $18{ }^{\circ} \mathrm{C}(\mathrm{A})$ and $23{ }^{\circ} \mathrm{C}(\mathrm{B})$

At a higher supercooling, the effect of the additive is lower. Higher crystallization rates prevail and the opportunity to absorb at the growth sites is reduced (Boistelle, 1988). Nevertheless, only small amounts are required to cause an effect when the added component acts at growth sites. As expressed by Mullin (1993) this can result in a change of crystal morphology. The specific influence of an additive therefore depends on whether a molecule has been completely integrated into a crystal and becomes "grown over", or whether the difference in structure is so big that further growth is blocked.

\section{Conclusion}

Our studies has shown that even the smallest amounts of minor components have a significant effect on the crystallization properties of fats. In addition, the impact of known FFA as additives in CB without FFA content has been described in more detail. Moreover the aspect of tempering and its influence on added free fatty acids was considered for the first time.

Minor components like free fatty acids show a significant influence on the crystallization kinetics of cocoa butter under both spontaneous and pre-crystallized conditions. With increasing temperature, reduced crystallization rates, lower solid fat contents and longer induction times occur. At higher temperatures, palmitic acid and especially stearic acid act as a crystallization initiator due to their higher melting point, indicating shorter induction times with increasing FFA content. Although pure cocoa butter crystallizes fastest, an increasing stearic acid content leads to higher crystallization rates. In contrast, palmitic and oleic acid have retarding effects. In this case, a temperature dependence under spontaneous conditions was found, while after pre-crystallization, the free fatty acid concentration could be identified as the driving force in terms of crystallization rate. Although palmitic acid differs from stearic acid only by the length of two C-atoms, lower concentrations lead to a strong reduction in crystallization rate and has an intense influence on the duration and extent of the $\alpha$-modification. Moreover, there was a significant difference in solid fat content between spontaneously crystallized and pre-crystallized blends. It seems that the rearrangement to the more stable polymorphic forms leads to incorporation of additional fat molecules, which explains the higher SFC values of spontaneously crystallized cocoa butter. The content of free fatty acids only showed a significant influence on the SFC of pre-crystallized samples, whereby the difference in SFC did not correlate with the amount of fatty acid added. 
Thus, this research exhibits that even with small amounts of free fatty acids, a cocoa butter can be tailored to appropriate applications and requirements of the customer or the industry. The specific addition of certain free fatty acids in manageable quantities could avoid costly processing, refining or separation processes in fat industry in the future.

\section{References}

Ayala, J. V., Calliauw, G., Foubert, I., Dewettinck, K., Dyer, B., \& De Greyt, W. (2007). Impacts of bleaching and packed column steam refining on cocoa butter properties. Journal of the American Oil Chemists' Society, 84(11), 1069-1077. https://doi.org/10.1007/s11746-007-1130-9

Boistelle, R. (1988). Fundamentals of nucleation and crystal growth. In: Garti, N., \& Sato, K. (eds) Crystallization and polymorphism of fats and fatty acids, Surfactant Science series, 31. Marcel Dekker Inc., New York, 189-226.

Calliauw, G., Ayala, J. V., Gibon, V., Wouters, J., De Greyt, W., Foubert, I., \& Dewettinck, K. (2008). Models for FFA-removal and changes in phase behavior of cocoa butter by packed column steam refining. Journal of Food Engineering, 89(3), 274-284. https://doi.org/10.1016/j.jfoodeng.2008.05.002

Campos, R., \& Marangoni, A. G. (2012). Molecular composition dynamics and structure of cocoa butter. In: Garti, N., \& Widlak, N. R. (eds.) Cocoa Butter and Related Compounds. AOCS Press, Urbana, IL 61802, 213-233. https://doi.org/10.1016/B978-0-9830791-2-5.50008-6

Chaiseri, S., \& Dimick, P. S. (1989). Lipid and hardness characteristics of cocoa butters from different geographic regions. Journal of the American Oil Chemists' Society, 66(12), 1771-1776. https://doi.org/10.1007/BF02660745

Dewettinck, K., Foubert, I., Basiura, M., \& Goderis, B. (2004). Phase behavior of cocoa butter in a two-step isothermal crystallization. Crystal Growth \& Design, 4(6), 1295-1302. https://doi.org/10.1021/cg049772n

DIN EN ISO 8292-1:2008: Animal and vegetable fats and oils - Determination of solid fat content by pulsed NMR Part 1: Direct method

Foubert, I., Vanrolleghem, P. A., Vanhoutte, B., \& Dewettinck, K. (2002). Dynamic mathematical model of the crystallization kinetics of fats. Food Research International, 35(10), 945-956. https://doi.org/10.1016/S0963-9969(02)00157-6

Foubert, I., Dewettinck, K., \& Vanrolleghem, P. A. (2003b). Modelling of the crystallization kinetics of fats. Trends in Food Science \& Technology, 14(3), 79-92. https://doi.org/10.1016/S0924-2244(02)00256-X

Foubert, I., Vanrolleghem, P. A., \& Dewettinck, K. (2003a). A differential scanning calorimetry method to determine the isothermal crystallization kinetics of cocoa butter. Thermochimica acta, 400(1-2), 131-142. https://doi.org/10.1016/S0040-6031(02)00484-7

Foubert, I., Vanrolleghem, P. A., Thas, O., \& Dewettinck, K. (2004). Influence of chemical composition on the isothermal cocoa butter crystallization. Journal of Food Science, 69(9), 478-487. https://doi.org/10.1111/j.1365-2621.2004.tb09933.x

Foubert, I., Fredrick, E., Vereecken, J., Sichien, M., \& Dewettinck, K. (2008). Stop-and-return DSC method to study fat crystallization. Thermochimica acta, 471(1-2), 7-13. https://doi.org/10.1016/j.tca.2008.02.005

Gordon, M. H., \& Rahman, I. A. (1991). Effects of minor components on the crystallization of coconut oil. Journal of the American Oil Chemists' Society, 68(8), 577-579. https://doi.org/10.1007/BF02660154

Herrera, M., \& Rocha, F. M. (1996). Effects of sucrose ester on the kinetics of polymorphic transition in hydrogenated sunflower oil. Journal of the American Oil Chemists' Society, 73(3), 321-326. https://doi.org/10.1007/BF02523425

Herrera, M. L., de Leon Gatti, M., \& Hartel, R. W. (1999). A kinetic analysis of crystallization of a milk fat model system. Food Research International, 32(4), 289-298. https://doi.org/10.1016/S0963-9969(99)00083-6

Jacobsberg, B., \& Ho, O. C. (1976). Studies in palm oil crystallization. Journal of the American Oil Chemists' Society, 53(10), 609-617. https://doi.org/10.1007/BF02586272

Kloek, W., Walstra, P., \& Vliet, T. V. (2000). Crystallization kinetics of fully hydrogenated palm oil in sunflower oil mixtures. Journal of the American Oil Chemists' Society, 77(4), 389-398.

https://doi.org/10.1007/s11746-000-0063-z 
Lechter, A., Widlak, N., Sikorski, D., \& Karcher, G. (2011). Impact of Deodorization on the Crystallization Properties and Solidification Behavior of Cocoa Butter. AOCS Conference. Cincinnati, OH. https://doi.org/10.1016/B978-0-9830791-2-5.50012-8

Lechter, A. (2012). Effect of Minor Components on Cocoa Butter Polymorphism and Kinetics of Crystallization. In: Garti, N., \& Widlak, N. R. (eds.) Cocoa Butter and Related Compounds. AOCS Press, Urbana, IL 61802, 213-233. https://doi.org/10.1016/B978-0-9830791-2-5.50012-8

Lipp, E. M., \& Anklam, E. (1998). Review of cocoa butter and alternative fats for use in chocolate-part A. Compositional data. Food Chemistry, 62(1), 73-97. https://doi.org/10.1016/S0308-8146(97)00160-X

Loisel, C., Lecq, G., Keller, G., \& Ollivon, M. (1998). Dynamic crystallization of dark chocolate as affected by temperature and lipid additives. Journal of Food Science, 63(1), 73-79. https://doi.org/10.1111/j.1365-2621.1998.tb15679.x

MacNaughtan, W., Farhat, I. A., Himawan, C., Starov, V. M., \& Stapley, A. G .F. (2006). A differential scanning calorimetry study of the crystallization kinetics of tristearin-tripalmitin mixtures. Journal of the American Oil Chemists' Society, 83(1), 1-9. https://doi.org/10.1007/s11746-006-1167-1

Marangoni, A. G., \& McGauley, S. E. (2003). Relationship between crystallization behavior and structure in cocoa butter. Crystal Growth \& Design, 3(1), 95-108. https://doi.org/10.1021/cg0255801

Mullin J. W. (1993). Crystal growth. In: Mullin J. W. (ed) Crystallization, 3rd ed. Butterworth-Heinemann, Oxford, 202-263.

Padar, S., Jeelani, S. A. K., \& Windhab, E. J. (2008). Crystallization kinetics of cocoa fat systems: experiments and modeling. Journal of the American Oil Chemists' Society, 85(12), 1115-1126. https://doi.org/10.1007/s11746-008-1312-0

Pontillon, J. (1998). Cocoa and chocolate: production, utilization, characteristics. Technique \& Documentation.

Schlichter, A. J., Sarig, S., \& Garti, N. (1988.) Dynamic control of polymorphic transformation in triglycerides by surfactants: the button syndrome. Journal of the American Oil Chemists' Society, 65(7), 1144-1150. https://doi.org/10.1007/BF02660571

Schuster-Salas, C., \& Ziegleder, G. (1992). DSC-Messung des Temperiergrades fliessfähiger vorkristallisierter Schokolademassen unter Produktionsbedingungen. Zucker- und Süsswaren-Wirtschaft, 45(9), 324-326.

Smith, P. R., Cebula, D. J., \& Povey, M. J. (1994). The effect of lauricbased molecules on trilaurin crystallization. Journal of the American Oil Chemists' Society, 71(12), 1367-1372. https://doi.org/10.1007/BF02541357

Smith, K. W., Bhaggan, K., Talbot, G., \& van Malssen, K. F. (2011). Crystallization of fats: influence of minor components and additives. Journal of the American Oil Chemists' Society, 88(8), 1085-1101. https://doi.org/10.1007/s11746-011-1819-7

Tietz, R. A., \& Hartel, R. W. (2000). Effects of minor lipids on crystallization of milk fat-cocoa butter blends and bloom formation in chocolate. Journal of the American Oil Chemists' Society, 77(7), 763-771. https://doi.org/10.1007/s11746-000-0122-5

Vanhoutte, B., Dewettinck, K., Foubert, I., Vanlerberghe, B., \& Huyghebaert, A. (2002). The effect of phospholipids and water on the isothermal crystallisation of milk fat. European Journal of Lipid Science and Technology, 104(8), 490-495.

https://doi.org/10.1002/1438-9312(200208)104:8<490::AID-EJLT490>3.0.CO;2-U

Ziegleder, G. (1990). DSC - Thermoanalyse und Kinetik der Kristallisation von Kakaobutter. European Journal of Lipid Science and Technology, 92(12), 481-485. https://doi.org/10.1002/lipi.19900921207

Ziegleder, G. (1995). Kristallisation fetthaltiger Massen, dargestellt an Beispielen aus der Schokoladentechnologie. TU München, Habilitation.

Zwietering, M. H., Jongenburger, I., Rombouts, F. M., \& Van't Riet, K. (1990). Modeling of the bacterial growth curve. Applied and environmental microbiology, 56(6), 1875-1881. American Psychological Association. (1972). Ethical standards of psychologists. Washington, DC: American Psychological Association.

\section{Copyrights}

Copyright for this article is retained by the author(s), with first publication rights granted to the journal.

This is an open-access article distributed under the terms and conditions of the Creative Commons Attribution license (http://creativecommons.org/licenses/by/4.0/). 